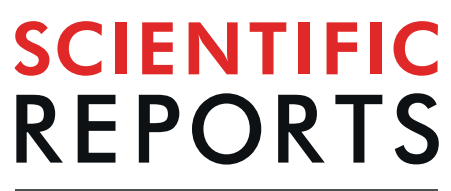

natureresearch

\title{
OPEN
}

Published online: 15 April 2020

\section{Author Correction: Angiotensin- converting enzyme inhibitors or angiotensin receptor blocker monotherapy retard deterioration of renal function in Taiwanese chronic kidney disease population}

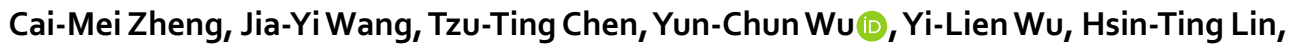
Sheng-Po Chiu, Tian-Jong Chang, Jing-Quan Zheng, Nain-Feng Chu, Yu-Me Lin, Sui-Lung Su, Kuo-Cheng Lu, Jin-Shuen Chen, Fung-Chang Sung, Chien-Te Lee, Yu Yang, Shang-Jyh Hwang, Ming-Cheng Wang, Yung-Ho Hsu, Hung-Yi Chiou, Senyeong Kao, Mei-Yi Wu \& Yuh-Feng Lin

Correction to: Scientific Reports https://doi.org/10.1038/s41598-019-38991-z, published online 25 February 2019

The original version of this Article contained an error in Affiliation 2, which was incorrectly given as 'Department of Internal Medicine, School of Medicine, College of Medicine, Taipei Medical University, Taipei, Taiwan' The correct affiliation is listed below:

Division on Nephrology, Department of Internal Medicine, School of Medicine, College of Medicine, Taipei Medical University, Taipei, Taiwan

In addition, in Figure 1 the bottom right panel was incorrectly labelled as 'ACEI/ARB users'.

These errors have now been corrected in the HTML and PDF versions of the Article.

(i) Open Access This article is licensed under a Creative Commons Attribution 4.0 International License, which permits use, sharing, adaptation, distribution and reproduction in any medium or format, as long as you give appropriate credit to the original author(s) and the source, provide a link to the Creative Commons license, and indicate if changes were made. The images or other third party material in this article are included in the article's Creative Commons license, unless indicated otherwise in a credit line to the material. If material is not included in the article's Creative Commons license and your intended use is not permitted by statutory regulation or exceeds the permitted use, you will need to obtain permission directly from the copyright holder. To view a copy of this license, visit http://creativecommons.org/licenses/by/4.0/.

(C) The Author(s) 2020 